تأثير الإطعام طويل الأمد بجذور الجزر (Daucus carota) في بعض المؤشرات الوراثة الخلوية في الفئران البيض

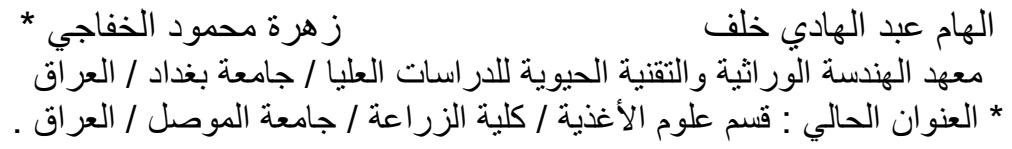

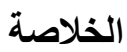

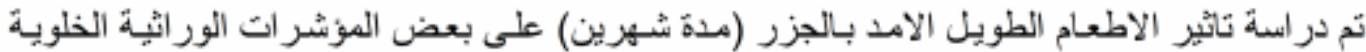

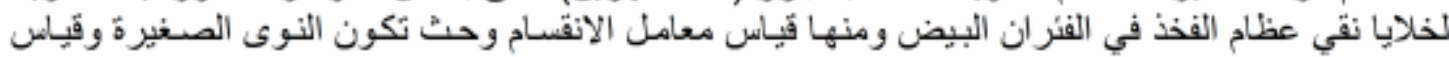

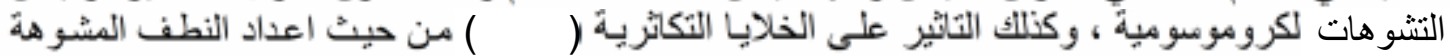

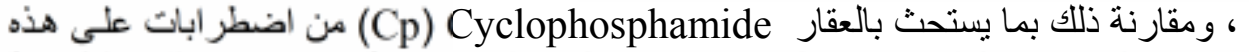

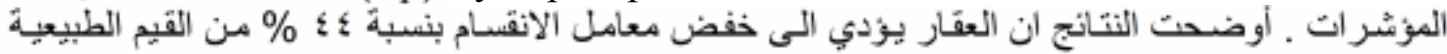

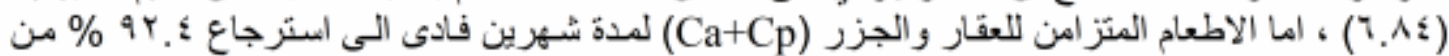

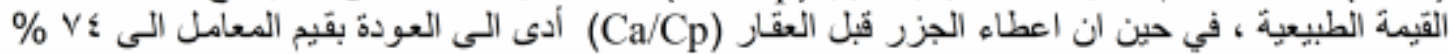

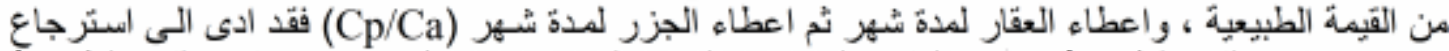

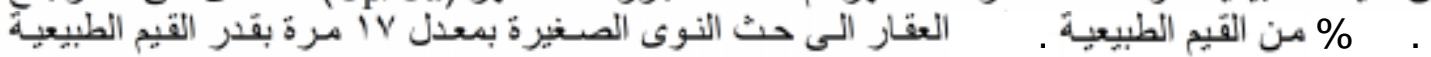

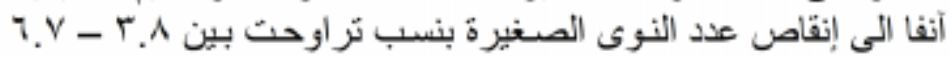

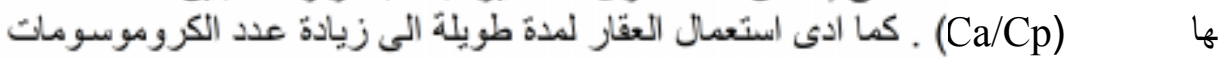

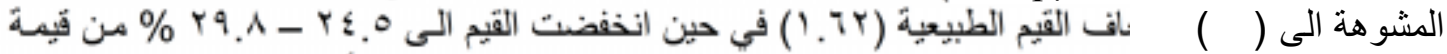

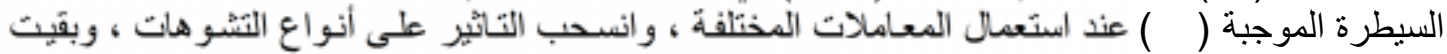

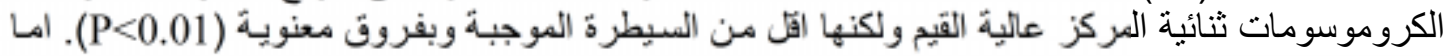

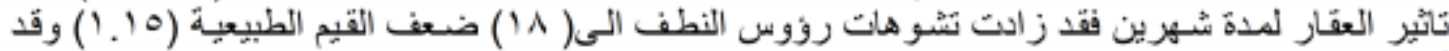

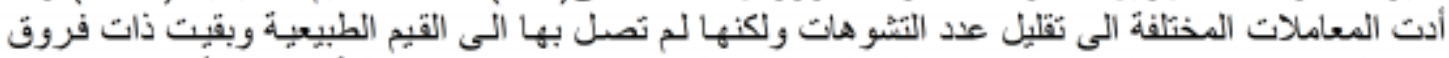

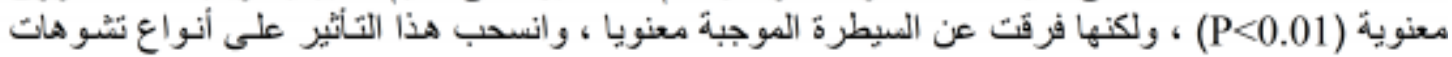

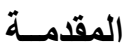

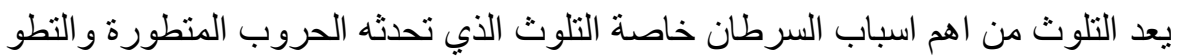

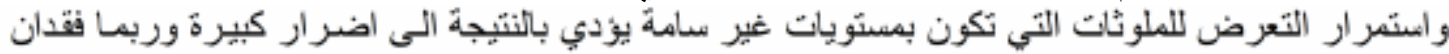

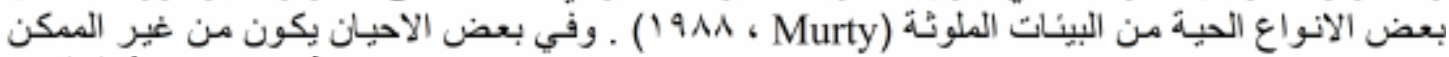

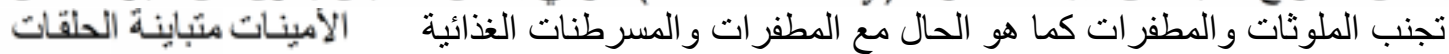
Heterocyclic amines

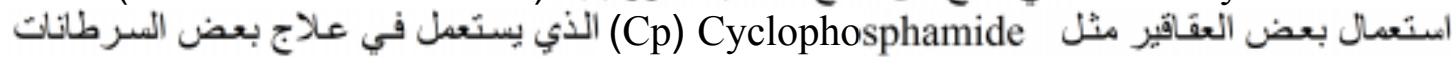

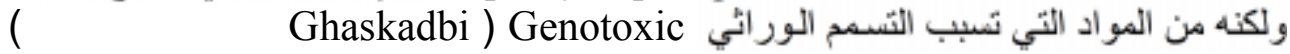
ان يتعرض لعمليات الايض داخل الجسم والتي تنتج مسرطنات نهائية ( Stoltz

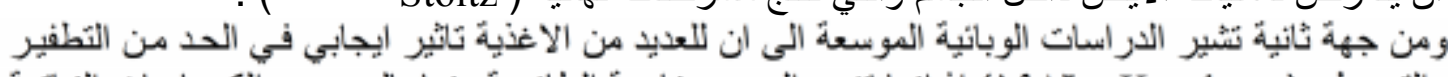

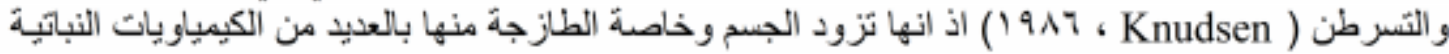

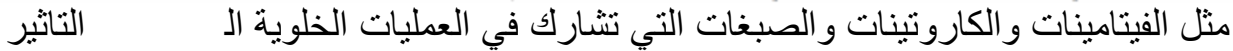

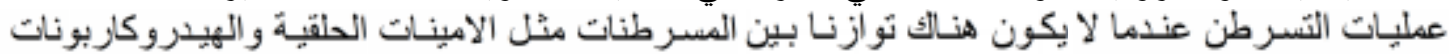

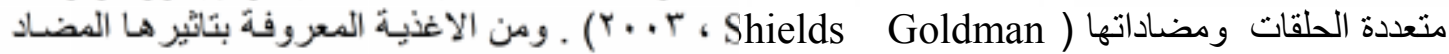

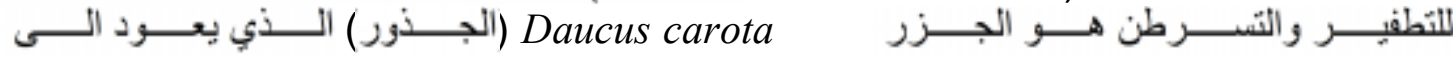

تاريخ تسلم البحث / / / م وقبوله / / /


العائلة الخيمية Umbelliferae ، ويحوي على العذيد من المركبات الفعالة مثل الفلافونـات و الكلابكوسبيات

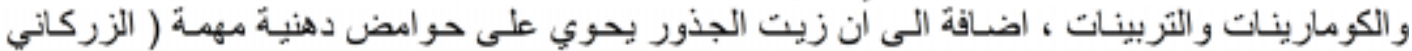

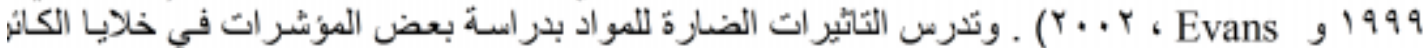

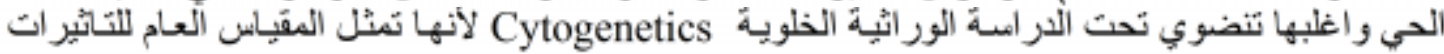

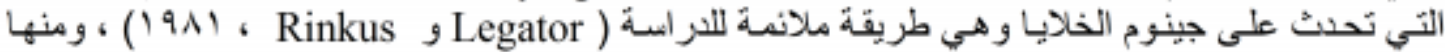

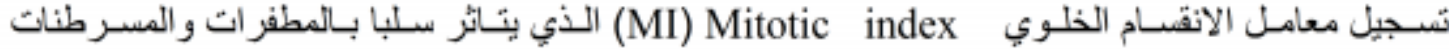

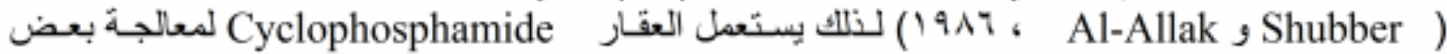
السرطانات و هو من Cytostatic drugs اذ ينّداخل مـع آليبة الانقسـام الخلوي (Belisario و واخرون ،

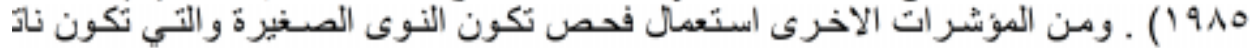

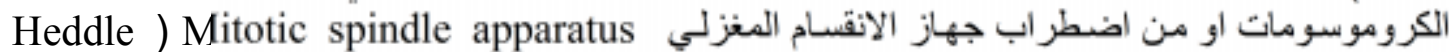

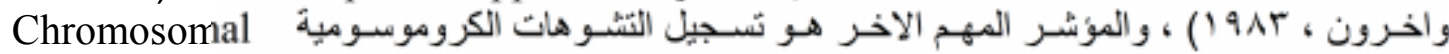
aberrations

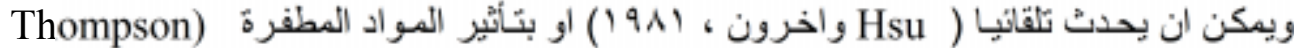

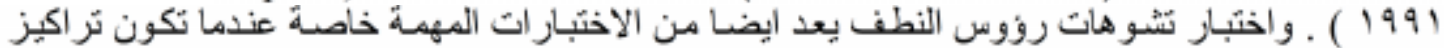

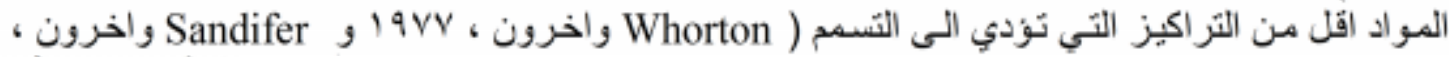
) وذللك لان النطف تكون ذات طبيعة خاصة وت وي على مو اد ور اثية بشكل وتنظلو من معظم مقومات الخلية الاخرى ( Phillips

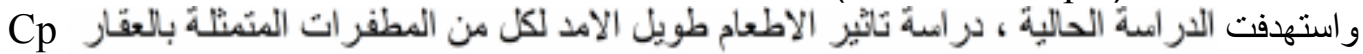

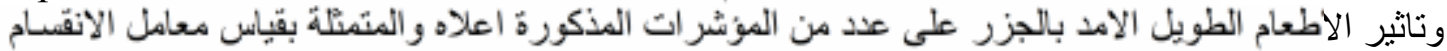

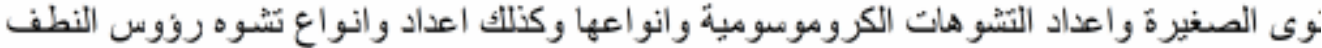

\section{مواد البحث وطر ائقه}

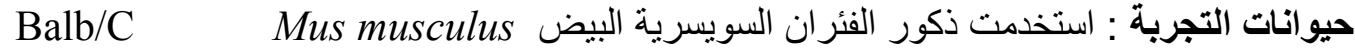

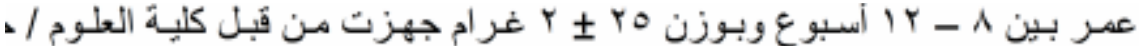

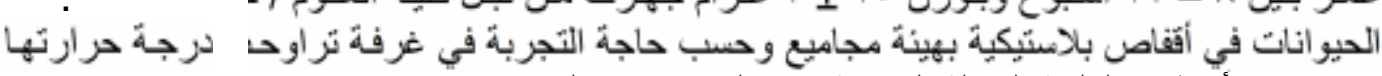

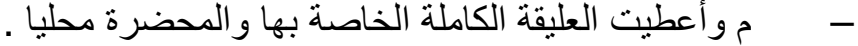

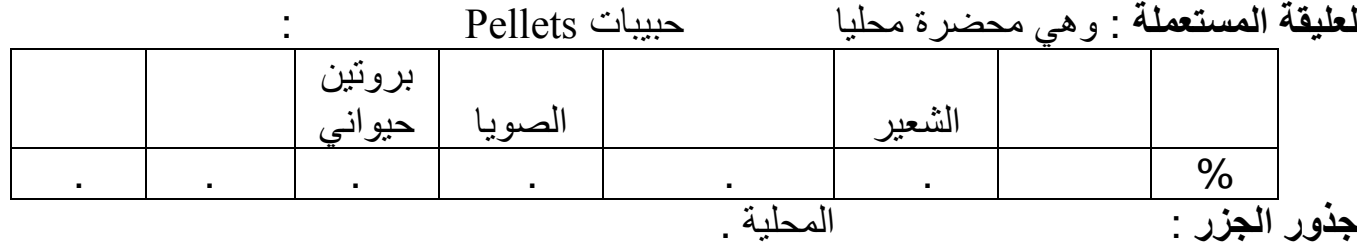

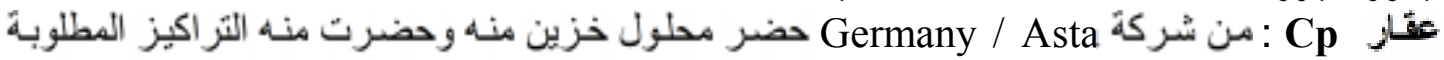

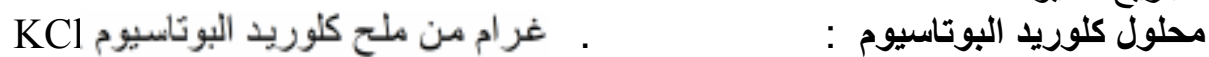

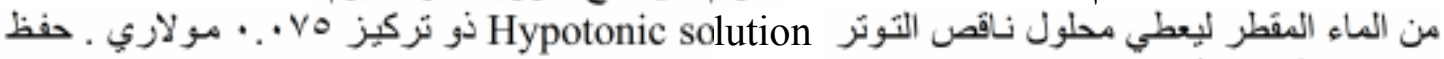

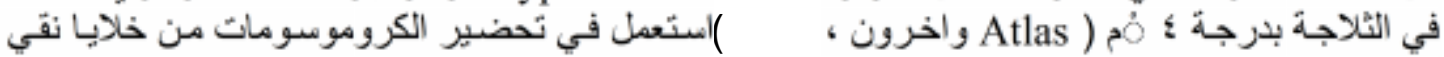

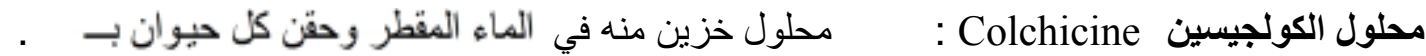
Intraperitoneal

التشريح بمدة - ساعة واستخدم المحلول انبا بعد تحضيره

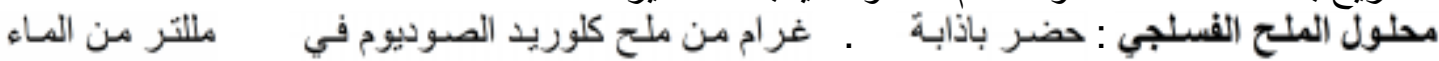

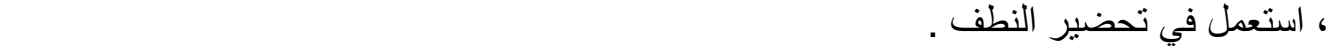

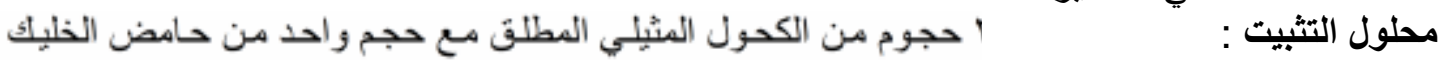
(Glacial acetic acid) 
محلول صبغة كمزا Giemsa stain solution : حضر واستُعل في تصبيغ الثراث

$$
\text { و النوى الصغيرة ( Metcalf }
$$

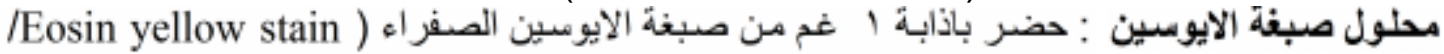
(England ， BDH ( Bruce Wyrobek )

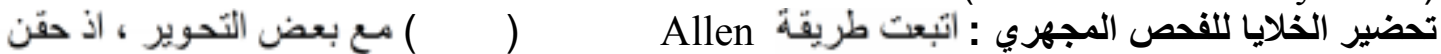

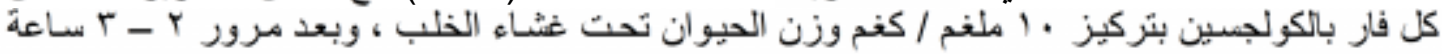

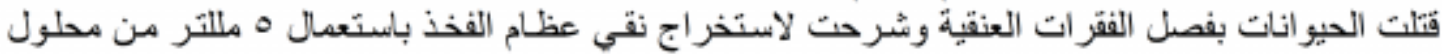

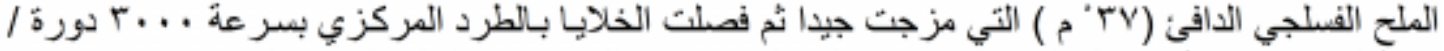

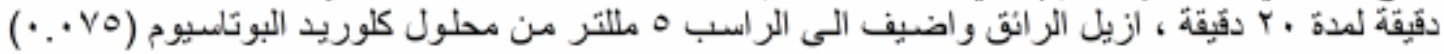

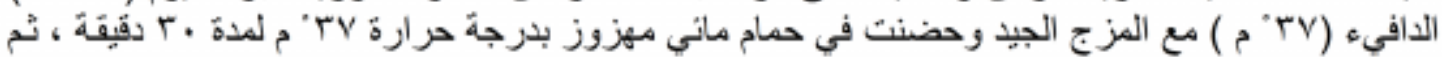

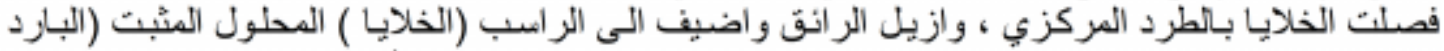

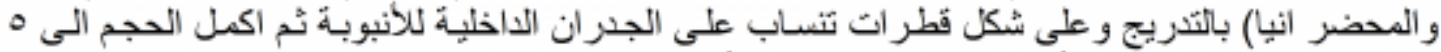

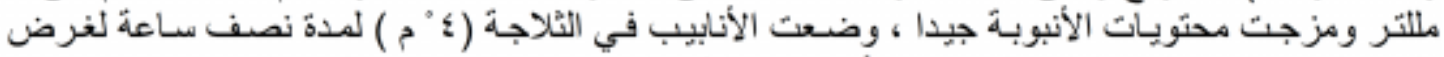

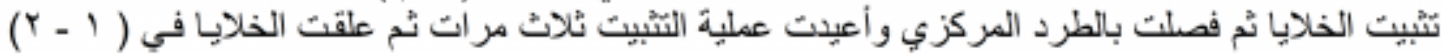

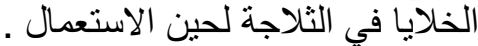

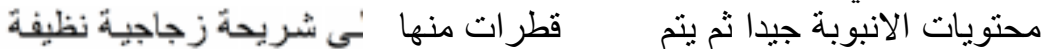

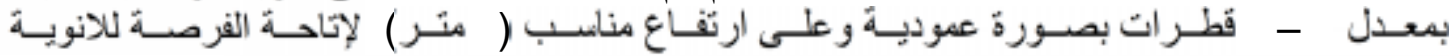

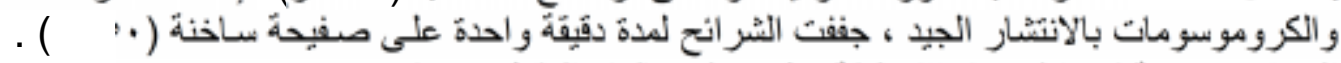

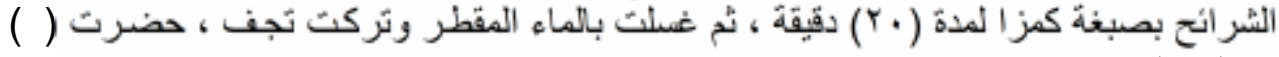

(MI) Mitotic index assay خلية منقسمة وغير منقسمة وحسبت النسبة المئوية لمعامل
حيو ان و استخدم

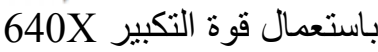

Al-Allak Shubber )

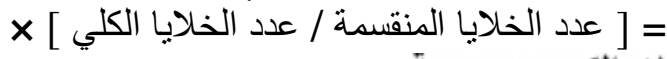

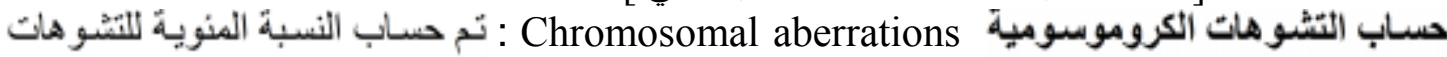

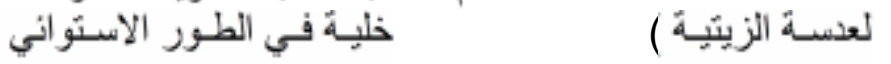

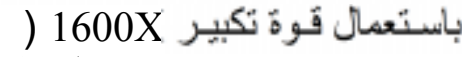
Metaphase

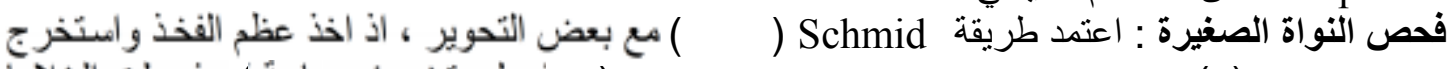

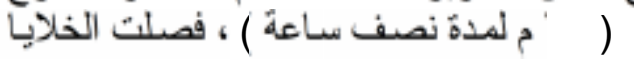

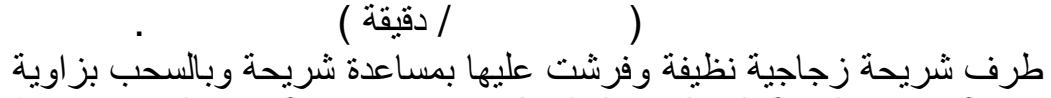

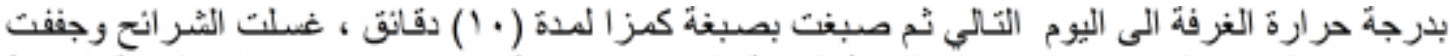

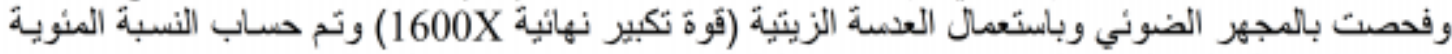

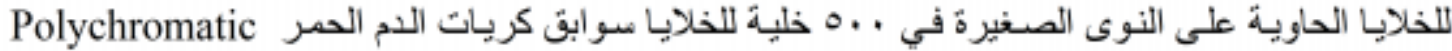

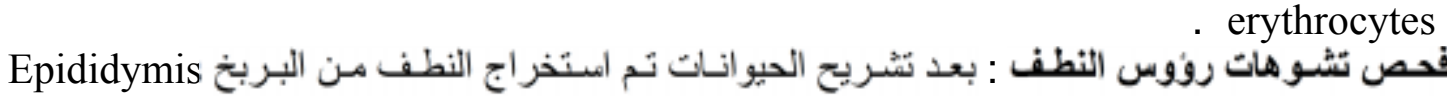

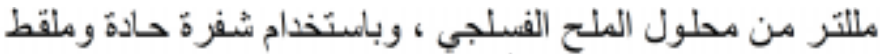

باستخدام طريقة فيقات

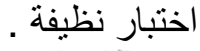

دقيق تم تقطيع البربخ الى قطع صغيرة جدا ، وضع النموذج الذئ

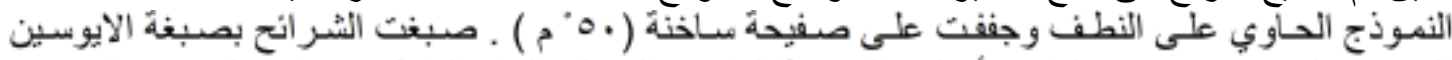

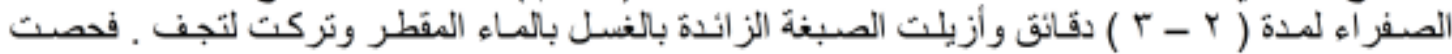

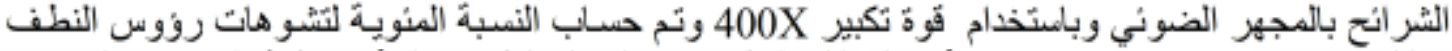

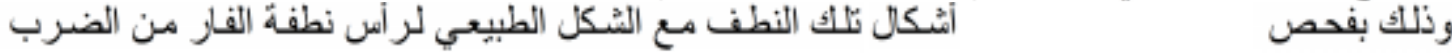



( ) ( )

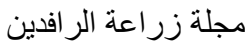

، و وامنّمرت التُجربة لمدةُ بوم ، واجريت لها المعاملات معاملة الحيوانات :

العليقةة العادية وتُشرب الماء العادي لمدة شُهرين ، وخصص لهيا

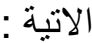

Cp العيطرة الموجبة : تركت الحيوانات تأكل العليقة العادية وتثرب الماء العادي ولكن كانت تجرع بالعقار )

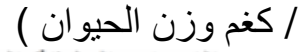

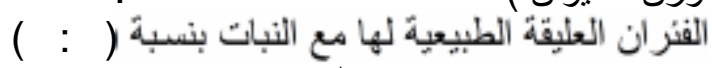

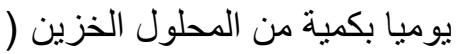

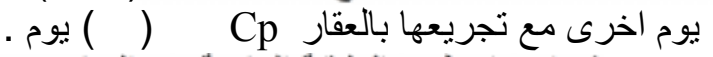
فئران و اعطيت العليقة العادية مع النبات بنسبة

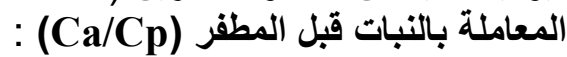

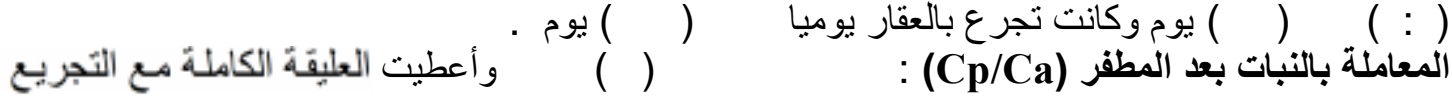

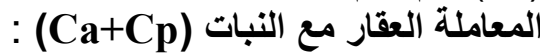

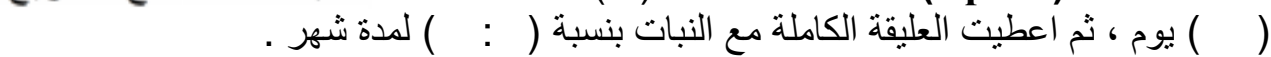

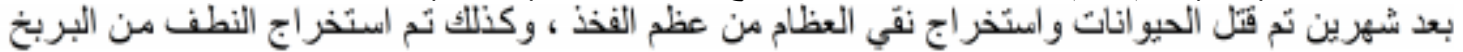

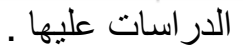

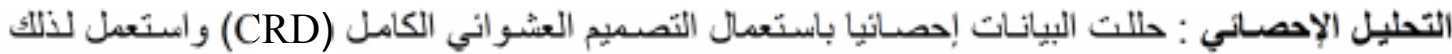

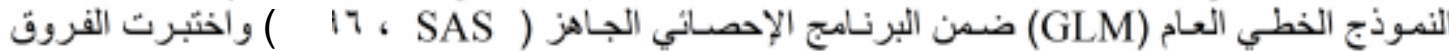

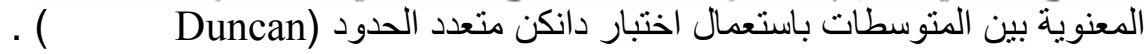

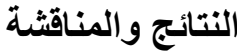

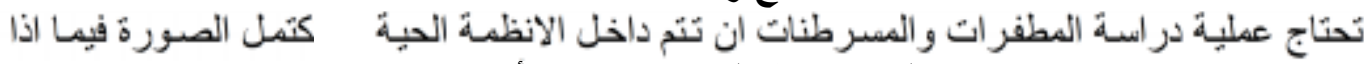

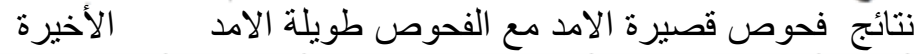

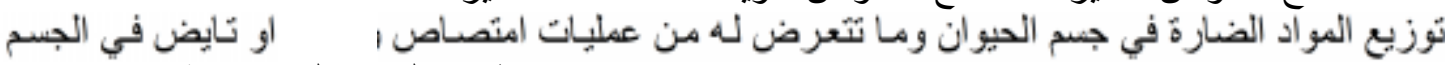

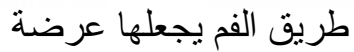

) وكنلك الدال مع البروتينيات الاخرى مثنل بروتينيات

Kassie )

Heddle )

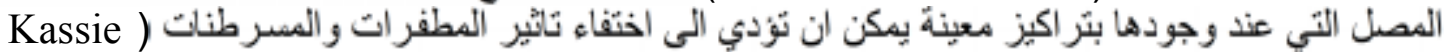

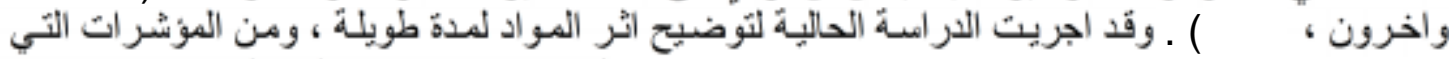

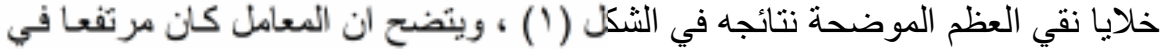

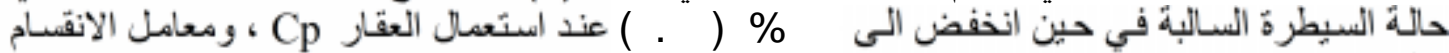

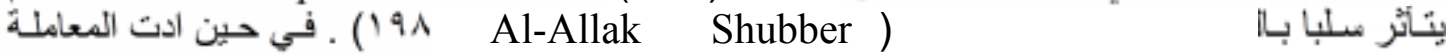

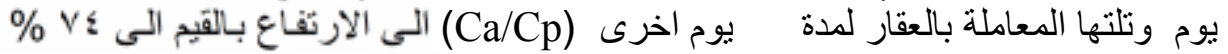

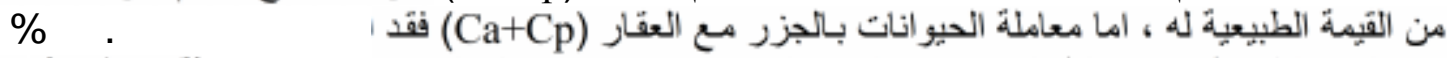

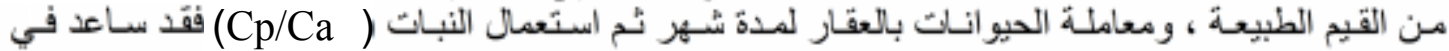

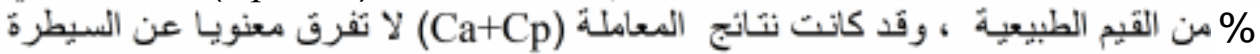

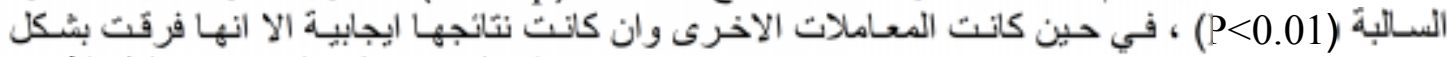

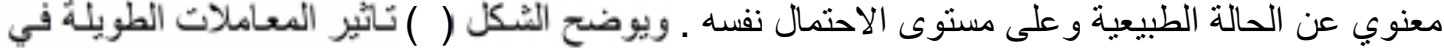

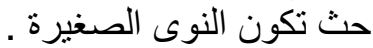

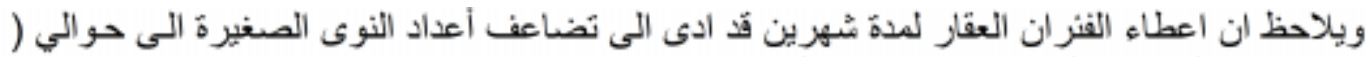

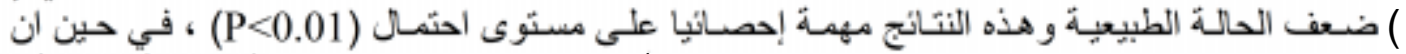

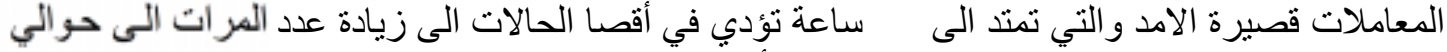

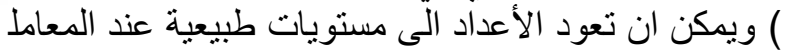

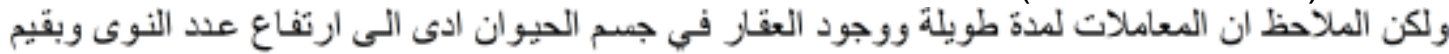

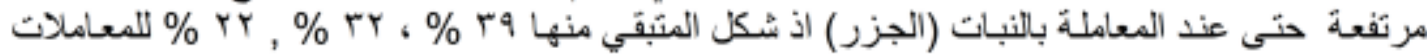

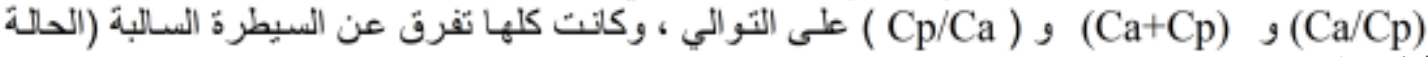

$$
\text { الطبيعية (P<0.01) ( }
$$




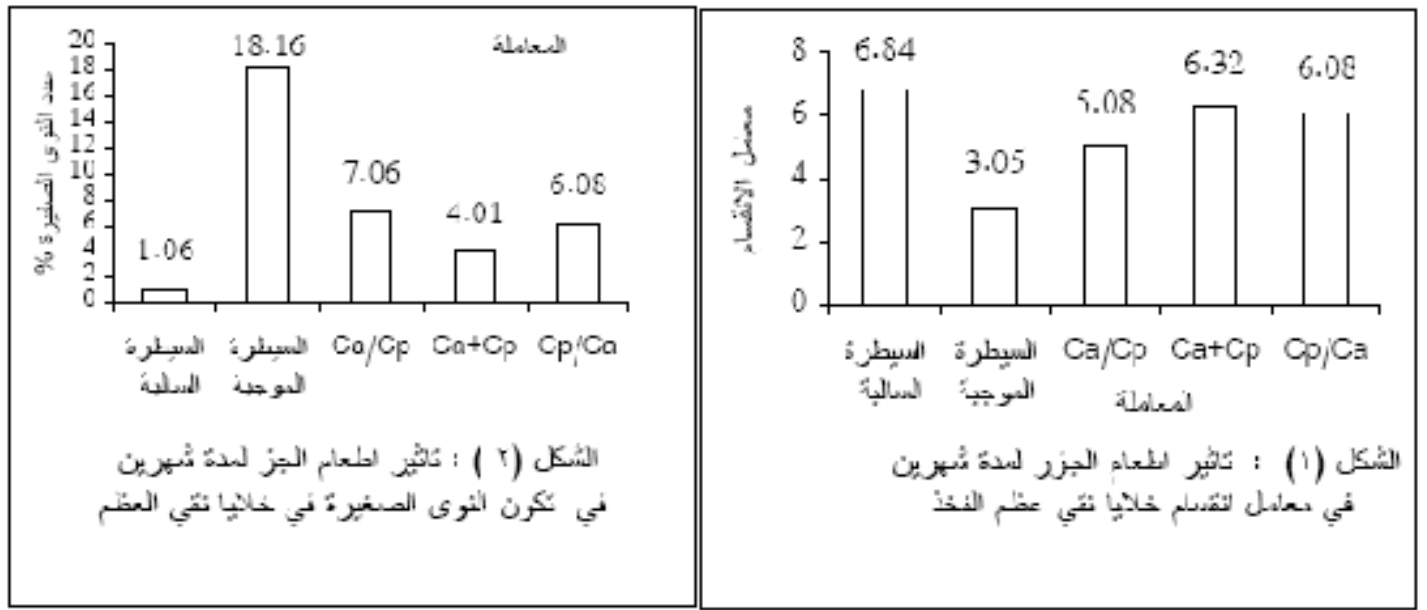

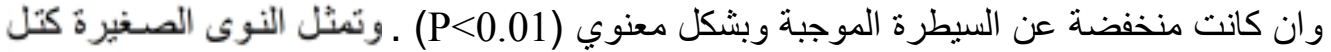

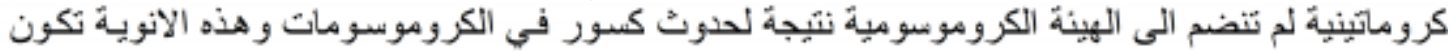

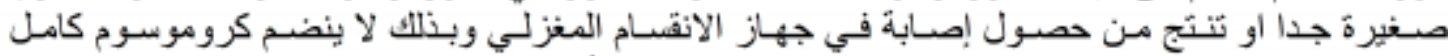

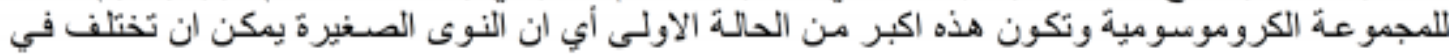

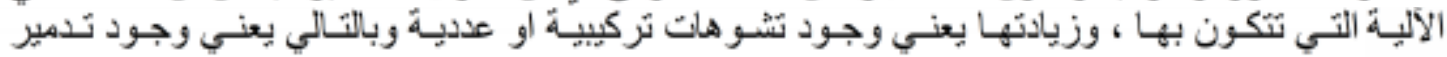

Tawn Salamone Heddle

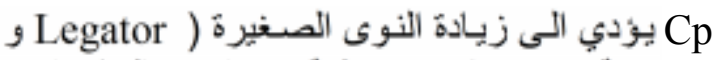
） Rinkus

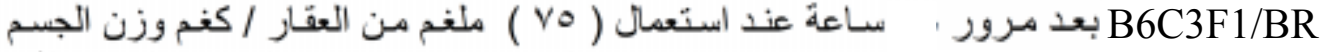

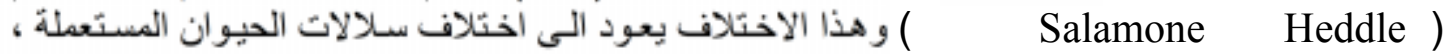

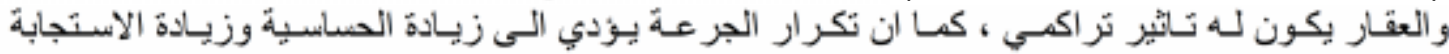

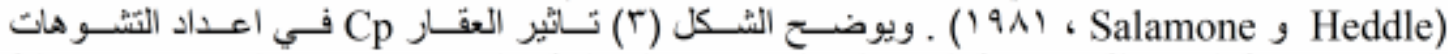

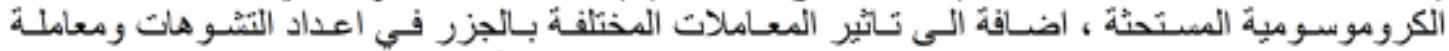

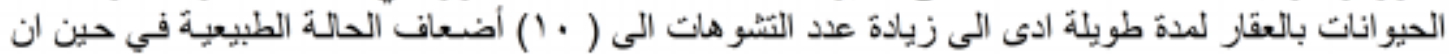

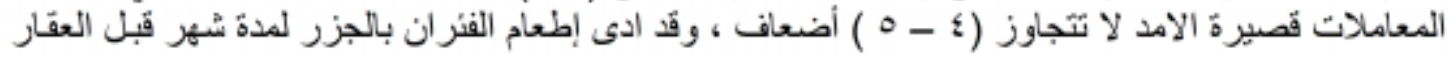

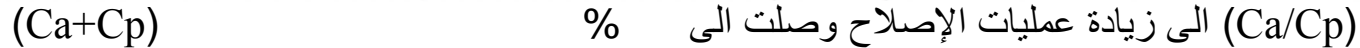

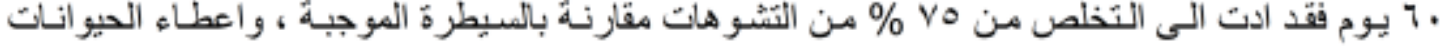

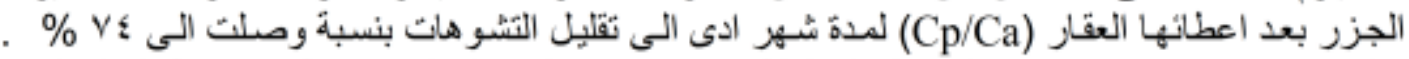

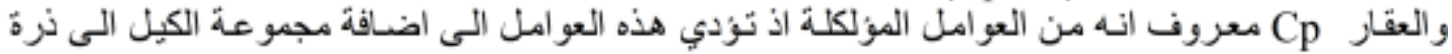

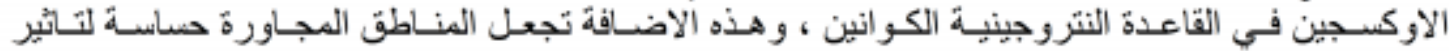

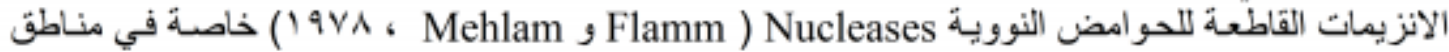

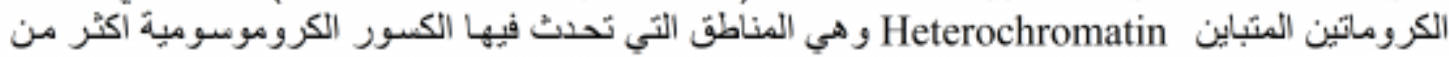

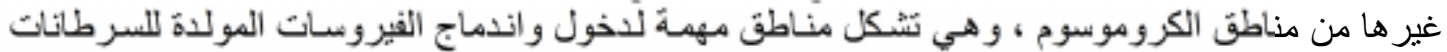

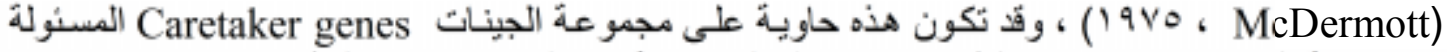

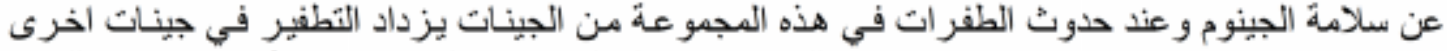

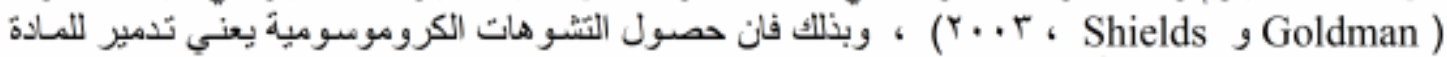
الور اثية ومقدمة لتطور الأور ام والسرطانات ـ اما تفاصيل انواع التشوهات فموضحة في الثكل ( ) ل 


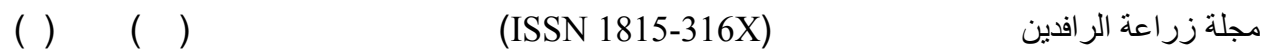
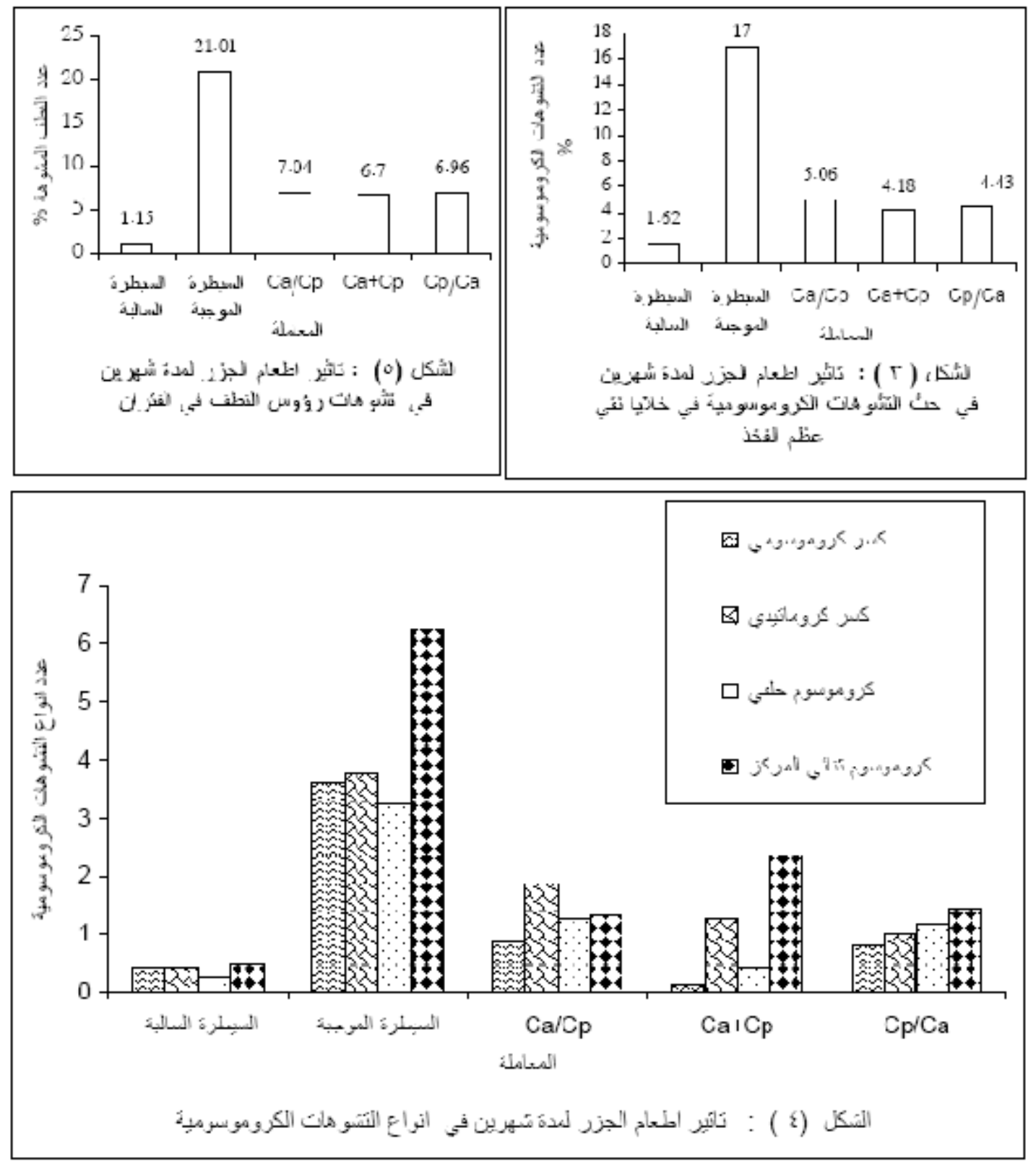

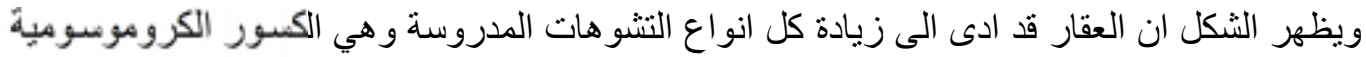

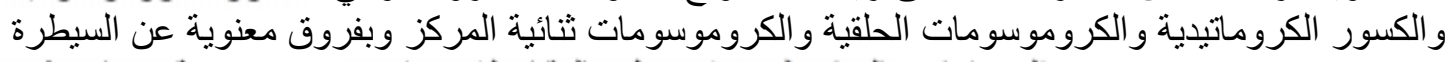

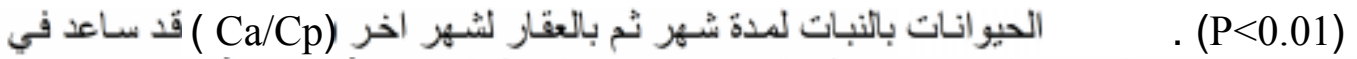

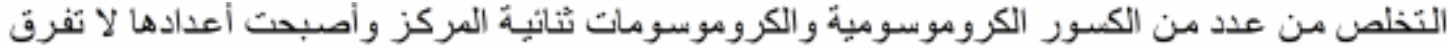

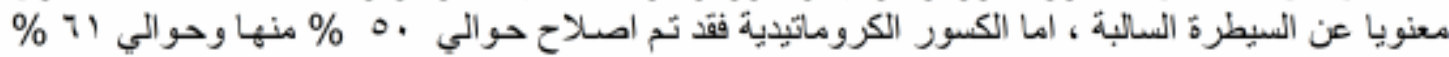

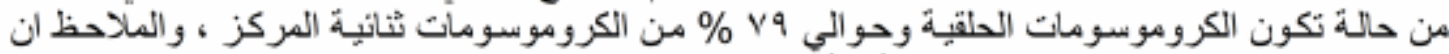

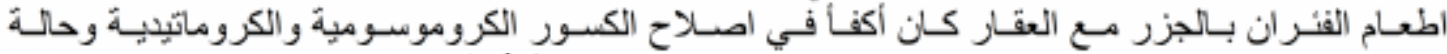

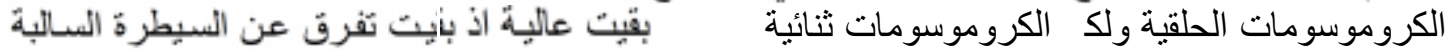

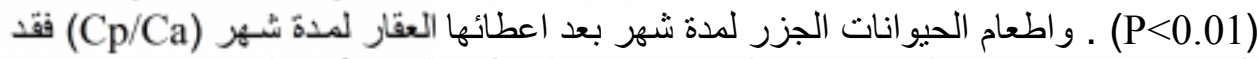

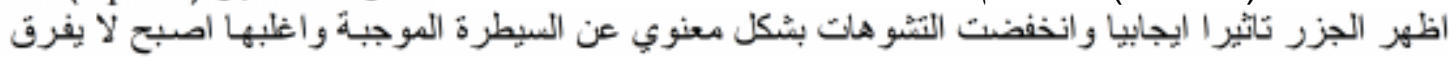

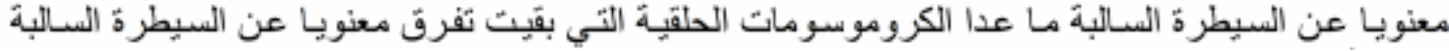

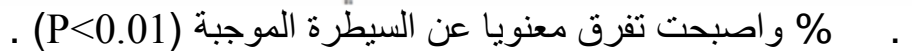
ولكنها

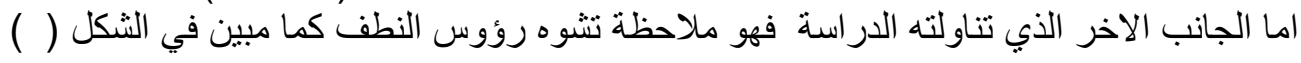




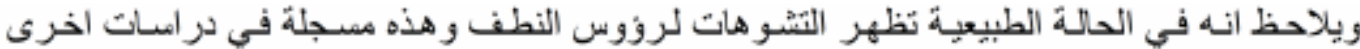

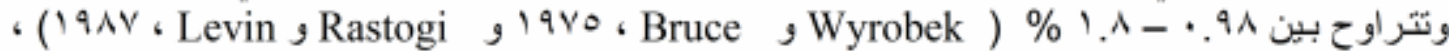

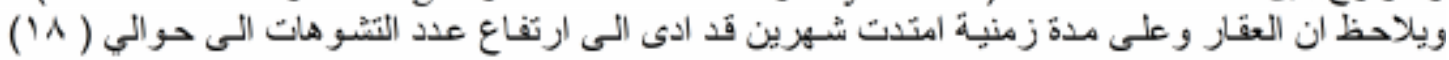

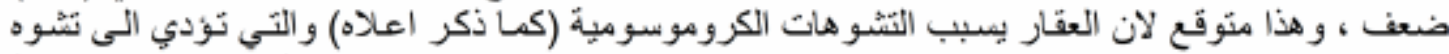

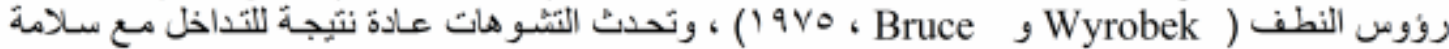

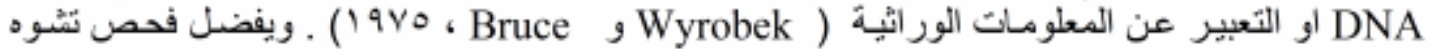

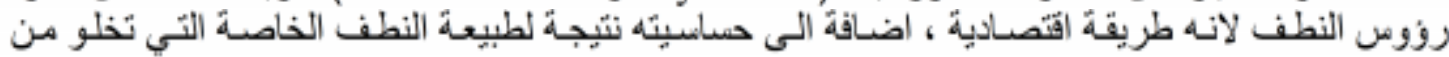

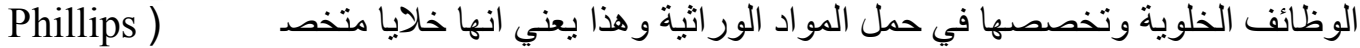

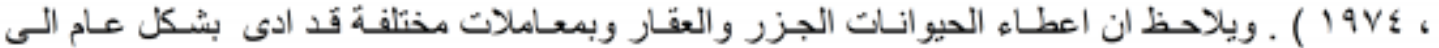

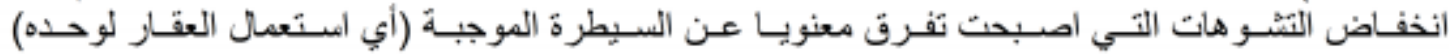

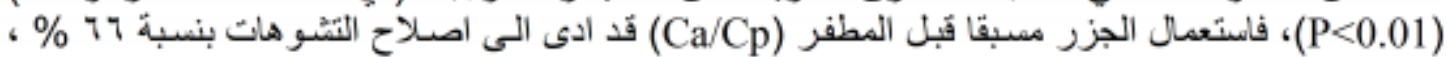

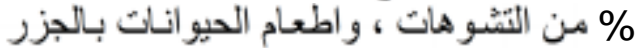

$$
\text { \% وهي حالة مقاربة للمعاملة (Ca/Cp) . }
$$

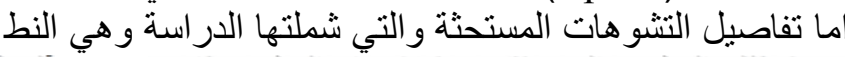

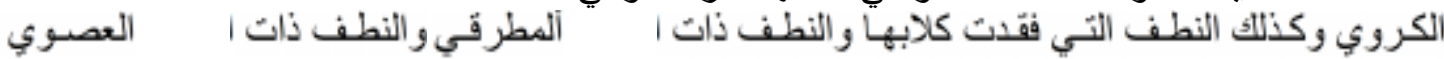

فموضحة تفاصيلها في الثكل ( )

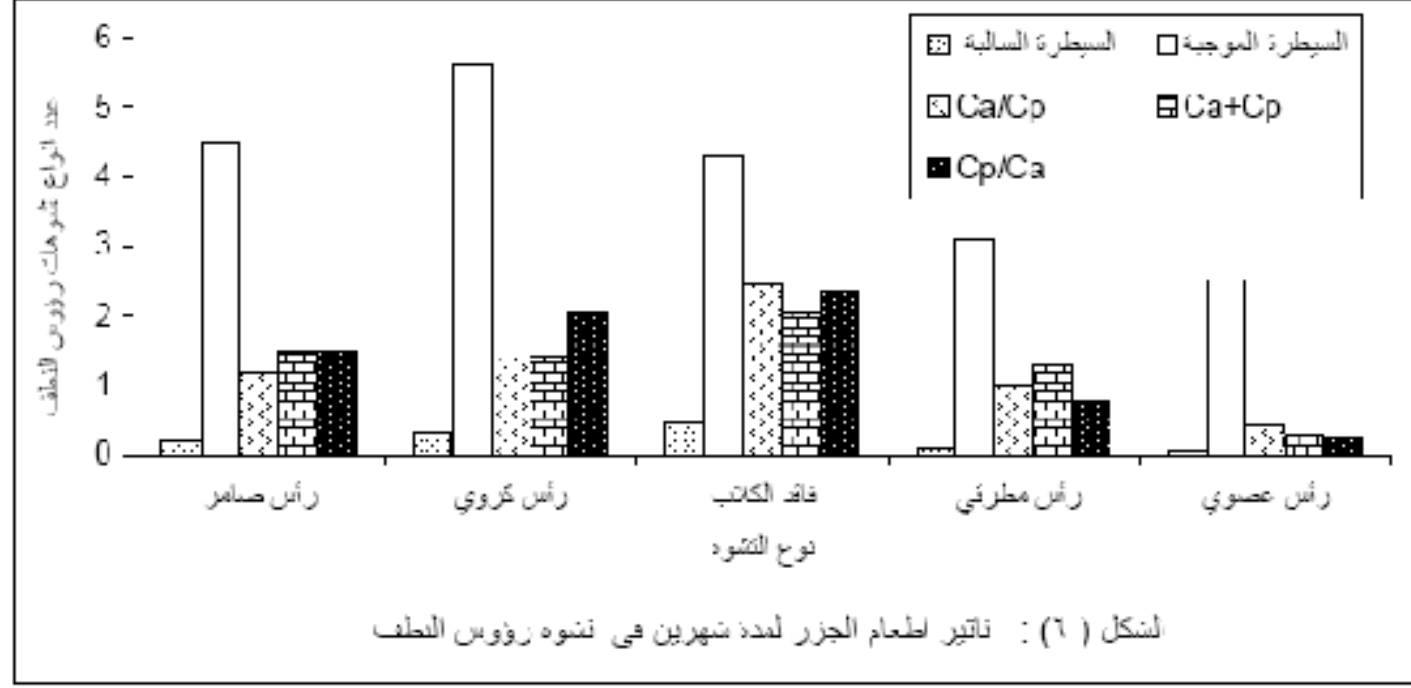

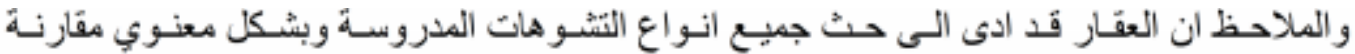

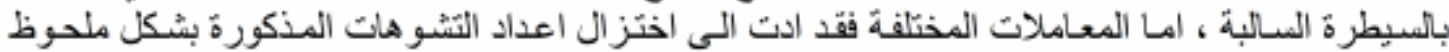

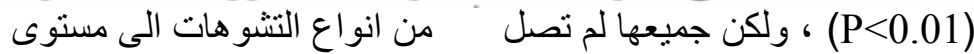

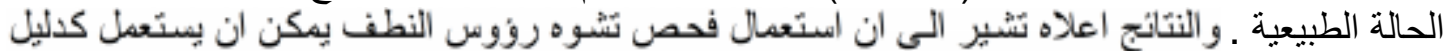

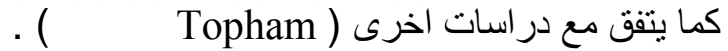

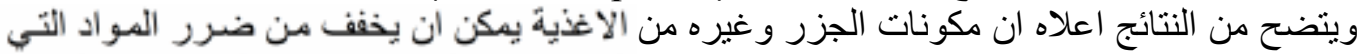

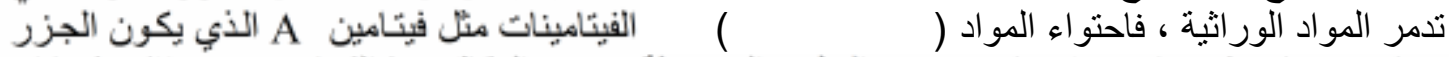

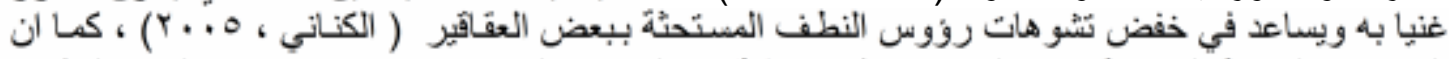

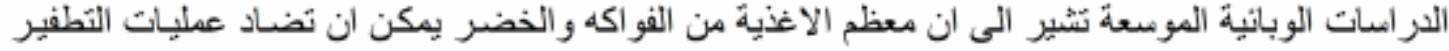

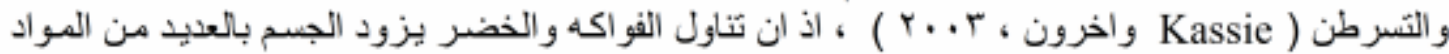

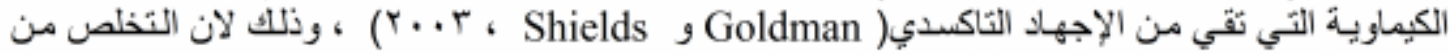

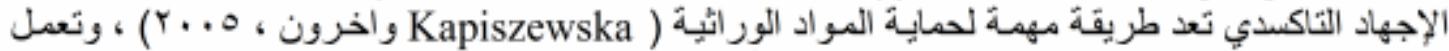

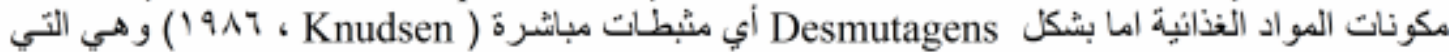

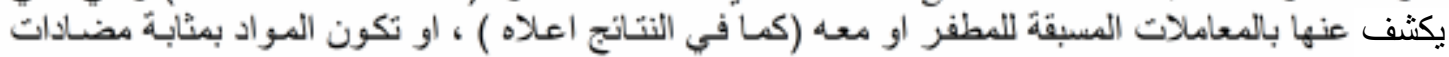

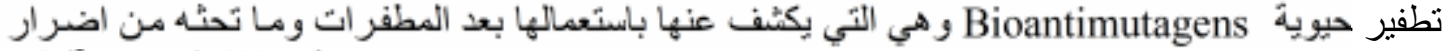

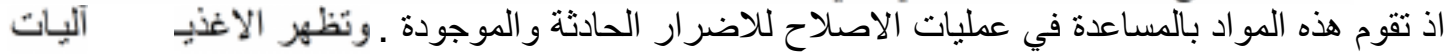




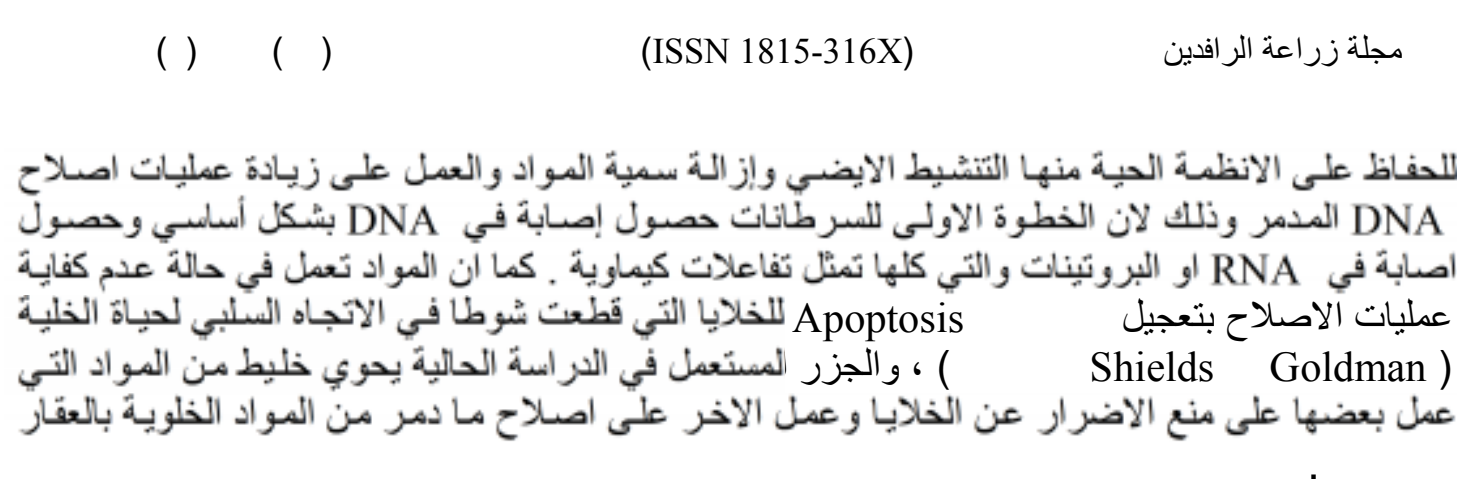

\title{
EFFECT OF LONG TERM ADMINISTRATION OF CARROT ROOTS (Daucus carota) ON SOME CYTOGENETIC PARAMETERS IN WHITE MICE
}

\author{
Ilham A. Khalaf \\ Zahra M. Al-Khafaji* \\ Institute of Genetic Engineering \& Biotechnology for Postgraduate Studies / University of \\ Baghdad / IRAQ . \\ * Present address : Dept. of Food Science / University of Mosul / IRAQ.
}

\begin{abstract}
The effect of long term administration of carrot roots (2 months) on some cytogenetic parameters in bone marrow cells of white mice was studied, these included, mitotic index (MI), micronuclei formation (Mn ), and chromosomal aberrations ( $\mathrm{Ch}$. ab .) of different types . In addition the effect was studied in germ cells (Sperms) by scoring the number and types of sperm - head abnormalities in comparison of the effect induced by cyclophosphamide $(\mathrm{Cp})$. Results showed that $\mathrm{Cp}$ reduced the MI to about $44 \%$ of the normal value (6.84), administration of carrot before the drug $(\mathrm{Ca} / \mathrm{Cp})$ raised the index to $74 \%$ of the normal value, while administration of carrot with the drug $(\mathrm{Ca}+\mathrm{Cp})$ restored $92.4 \%$, and administration of $\mathrm{Cp}$ followed by carrot $(\mathrm{Cp} / \mathrm{Ca})$ restored $88.9 \%$ of the normal value . Cp induced $\mathrm{Mn}$ to about 17 times of the baseline value 1.06 .The different treatments with carrot reduced the $\mathrm{Mn}$ to $3.8-6.7$ times the natural values, and the $(\mathrm{Ca} / \mathrm{Cp})$ treatment was the best. $\mathrm{Cp}$ treatment for long time raised the $\mathrm{Ch} . \mathrm{ab}$. to about 10 times the natural value 1.62 , these values reduced upon administration of carrot to about $24.5-29.8 \%$ of the positive control 17 , and such effect extended to the types of $\mathrm{Ch}$. ab. except that of dicentric chromosomes which persisted with high values, but it was lower than the positive control with statistical difference $(\mathrm{P}<0.01)$. The drug increased the sperm - head abnormalities to about 18 times the natural background 1.15. Different treatments of carrot reduced the level of abnormalities with significant differences compared to positive control $(\mathrm{P}<0.01)$, but the abnormalities were higher than the negative control with statistical difference $(\mathrm{P}<0.01)$, these results were reflected on the types of abnormalities .
\end{abstract}




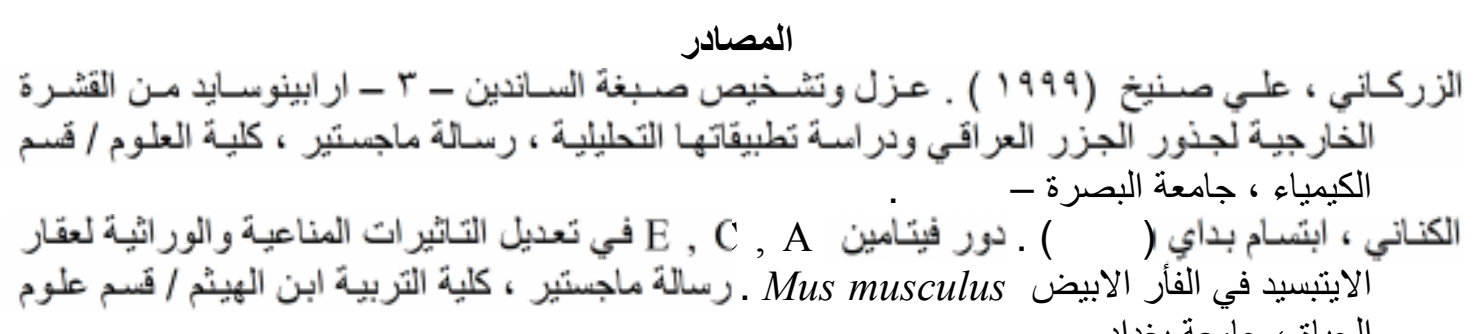

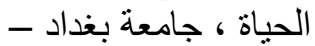

Allen , J ; C. Shuler; R. Mendes and S. Latt (1977). A simplified technique for in vivo analysis of sister chromatid exchange using 5-bromro-deoxy uridine . Cytogenet. Cell Genet. $18: 231-237$.

Atlas , R .; A. Brown and C . Parks (1995) . Manual of Experimental Microbiology . Mosby Co. New York .

Belisario , A . ; N . Panza, and G . Pacilia (1985). Effect of beta- carotene on mutagenic activity of some antineoplastics. Acta Vitaminol. Enzymol . 7: 75-78 .

Duncan ,D.(1955).Multiple range and multiple F- test .Biometric 11:1- 42

Evans , W. (2002). Treas and Evan's Pharmacognosy . $15^{\text {th }}$ Edition . W . B. Sanders Comp . Ltd . London, UK.

Flamm , W . and M . Mehlam (1978 ). " Advances in Modren Toxicology " vol . 5 . Mutagenesis . John Wiely and Sons, New York, London .

Ghaskadbi , S ; S. Rajmachikar ; C . Agate ; A. Kapadi and V . Vaidya . (1992) . Modulation of cyclophosphamide mutagenicity by vitamin $\mathrm{C}$ in vivo rodent micronucleus assay. Mutagens 12:11 -17.

Goldman, R . and P . Shields (2003) . Food Mutagens . J . Nutr. 133 : 965S-973S .

Heddle , J . ; M . Hiet ; B . Kirkhart ; K . Mavoumin ; J . MacGregor ; G . Newell and M . Salamone (1983). The induction of micronuclei as a measure of genotoxicity : A report of the U.S .Environmental Protection Agency gene- tox program . Mut . Res . $123: 61-118$.

Heddle, J. and M. Salamone (1981). The micronucleus Assay . I. In " Short-Term Tests for Chemical Carcinogens " . H. Stich and R. San (Eds.). Springer -Verlag : New York, Heidelberg .

Hsu , T . ; W , Au ; L . Strong and D . Johston (1981). A short - Term Cytogenetic Test for Genetic Instability in Human In "Short -Term Tests for Chemical Carcinogens " . H . Stich and R. San (Eds.). Springer - Verlag : New York, Heidelberg .

Kapiszewska , M . ; E . Soltys ; F . Visioli ; A . Cierniak and G . Zajac (2005) . The protective ability of the Mediterranean plant extracts against the oxidative damage. The role of the radical oxygen species and the polyphenol content . J . Physiol . Pharmacol . $56: 183-197$.

Kassie , F . ; B . Pool-Zobel ; W. Parzefall and S . Knasmuller (1999) . Genotoxic effects of benzyl isothiocynatate, a natural chemoprotective agent. Mutagenesis 14 : $595-604$.

Kassie , F.; M. Uhl; S. Rabot; Grasl-Kraup , B . ; R . Verker ; M. Kundi ; M . Chabicovsky ; R. Schultr-Hermann and S. Knasmuller (2003). Chemoprotective effects of 2amino- 3- methyl-imidazo[4,5-f] quinoline (IQ)- induced colonic and hepatic preneoplastic lesions in the F433 rat by cruciferous vegetables administrated simultaneously with carcinogen. Carcinogenesis $24: 255-261$.

Kinzler , K and B . Vogelstein (1998) . Landscaping the cancer terrain ., , Science 280 : $1036-1037$.

Knudsen, I. ( 1986) .Genetic Toxicology of the Diet . Alan R. Liss . New York .

Legator, M . and S. Rinkus (1981). Mutagenicity : Problems in Application in vitro . In " Short - Term Tests for Chemical Carcinogens ". H. Stich and R. San (Eds.) . Springer - Verlag : New York, Heidelberg . 

( ) ( )
(ISSN 1815-316X)
مجلة زر اعة الر افدين

McDermott, A . (1975) . Cytogenetics of Man and Other Animals . Chapman and Hall . London .

Metcalf . J . ; J . Gallin ; W . Nauseef and R . Root . (1986) . Laboratory Manual of Neutrophil Function . Revan Press : New York .

Murty, A. (1988) . Toxicity of Pesticides to Fish . vol II . CRC Press Inc . Boca Roton, Florida .

Phillips, D . (1974 ). Sperminogenesis . Academic Press . New York, London .

Rastogi, P . and R . Levin (1987). Induction of sperm abnormalities in mice by quercetin . Environ . Mutag . 9: 79-86.

Sandifer, S . ; R . Wikens ; C . Loadholt ; L . Lane and J . Eldridge (1979). Spermatogenesis in agricultural workers exposed to dibromochloropropane (DBCP). Bull. Environ. Contam . Toxicol . $423: 703-710$.

Schimd, W . (1976). The Cell Micronucleus Test for Cytogenetic Analysis . In " Chemical Mutagens : Principles and Methods for their Detection". A. Hollaender (Ed.) . Plenum : New York, Vol IV.

Shubber, E . and B . Al-Allak (1986). Spontaneous chromosomal aberrations and SCEs in human lymphocyte effect of culture conditions. Nucleus 29:92-98.

Stoltz , D . (1981). Detection of Cocarcinogens and Anticarcinogens with Microbial Mutagenicity Assays . In " Short - Term Tests for Chemical Carcinogens " . H . Stich and R. San (Eds.). Springer - Verlag : New

Tawn , E . and D . Holdsworth . (1992) .Mutagens Induced Chromosome Damage in Human Lymphocytes. In " Human Cytogenetic " Vol . II . D . Rooney and B . Czepukowski (Eds.) . Oxford University Press, UK .

Thompson , M . ; R. McInnes and H . Willard . (1991). Clinical Cytogenetics : General Principles and Autosomal Abnormalities . In . "Genetics in Medicine ". Saunders , W. B. Comp. UK.

Topham, J. (1980). The detection of carcinogen induced sperm head abnormalities in mice . Mut . Res . $69: 149-155$.

Whorton, D . ; R . Kraus ; S . Marshall and T . Milbt (1977). Infertility in male pesticides workers . Lancet $2: 1259-1261$.

Wyrobek, A . (1981). Methods for Human and Murine Sperm Assays . In " Short-Term Tests for Chemical Carcinogens" . H . Stich and R. San (Eds.) . Springer-Verlag : New York, Heidelberg .

Wyrobek, A . and W . Bruce (1975) . Chemical induction of sperm abnormalities in mice. Proc . Natl. Acad. Sci . $72: 4425-4429$. 